\title{
Plasma proteins in children with trichuris dysentery syndrome
}

Edward S Cooper, D Dan Ramdath, Camille Whyte-Alleng, Sharon Howell, Beryl E Serjeant

\begin{abstract}
Aims-To determine whether in Trichuris trichiura dysentery there is (1) evidence of a systemic inflammatory response, (2) evidence that the plasma protein disturbance has special characteristics compared with uninfected children in the endemic environment.
\end{abstract}

Methods-Three groups of children (age 1.6 to 11.4 years) were studied: 53 cases of trichuris dysentery syndrome (TDS), 16 cases of chronic non-secretory diarrhoea not infected with the parasite ("disease controls", DC), and 20 asymptomatic, parasite-free primary schoolchildren (normal controls, $\mathrm{NC}$ ). C reactive protein, $\alpha_{1}$ antitrypsin, caeruloplasmin, albumin, total globulin, fibrinogen, fibronectin, ferritin, and transferrin were measured on a single occasion for each. The study was thus a cross sectional descriptive survey for group comparison. Plasma viscosity was measured on admission for TDS and DC and repeated after six weeks and six months for TDS.

Results-Plasma C reactive protein, $\alpha_{1}$ antitrypsin, total globulin, fibronectin, and viscosity were significantly higher in TDS than in NC. DC children also had acute phase protein elevations ( $C$ reactive protein, caeruloplasmin, viscosity). However, the increase in caeruloplasmin was specific to the DC group while an increase in fibronectin was specific to the TDS group. Serial measurement of viscosity in TDS showed a modest but significant fall during the six months following treatment.

Conclusions-There is an acute phase response in intense trichuriasis and a specific elevation of plasma fibronectin. Plasma viscosity remains abnormally high six months after treatment, although lower than at diagnosis.

(f Clin Pathol 1997;50:236-240)

Keywords: Trichuris trichiura; acute phase response; fibronectin.

Trichuris trichiura is the agent of one of the most common parasitic infections of man. ${ }^{1}$ This intestinal nematode is harmless to the individual host when infection is light (when the worms are confined to the proximal colon), but causes a specific disease, trichuris dysentery syndrome (TDS), ${ }^{2}$ when infection is heavy. Worms will then be found throughout the colon, often in the terminal ileum, and in the rectal mucosa. TDS, like other types of colitis, presents as chronic, mucoid, bloody diarrhoea, anaemia, and stunting of growth. ${ }^{1}$ Since the parasite does not become established in the small intestine at any site proximal to the terminal ileum, and since even a heavy worm load in the colon does not represent more than about $10 \mathrm{~g}$ of parasite tissue, ${ }^{3}$ it is likely that these symptoms are manifestations of some form of inflammatory response to the worm by the host rather than metabolic activity of the worm itself

When using routine histology supplemented by immunostaining for markers of $\mathrm{T}$ cell activation, MacDonald et al were able to show little evidence of significant inflammation in the colonic mucosa of Jamaican children with TDS. ${ }^{4}$ However, the same group of investigators has provided evidence of an IgE mediated mucosal mast cell response ${ }^{5}$ as well as increased mucosal infiltration of cells producing calprotectin and the pro-inflammatory cytokine tumour necrosis factor $\alpha$ (TNF- $\alpha){ }^{6}$ Since there is also an increased plasma concentration of TNF- $\alpha$ in the systemic circulation of these children, ${ }^{6}$ there is direct evidence of a systemic consequence of intestinal mucosal inflammation.

We have measured the concentration of various plasma proteins expected to reflect the systemic component of an inflammatory response, comparing cases with children from similar backgrounds but lacking the parasitosis. The basic design of this study was thus a cross sectional descriptive survey for group comparison. We have also attempted to assess the response over time to chemotherapeutic worm expulsion through serial measurements of plasma viscosity, an integrated measure ${ }^{7}$ of the acute phase response.

\section{Methods}

Fifty three children with TDS were studied. These children (age range 1.8 to 11.4 years) were referred intermittently from clinics to take part in the growth and dysentery study at the Tropical Metabolism Research Unit (TMRU). ${ }^{3}$ TDS is a chronic condition without rapid changes of symptoms and the minimum duration of these children's symptoms was two months. During the child's short stay on the TMRU ward a colonoscopy was performed to assess the extent of inflammation and to estimate the number of worms in the colon. Regardless of the number in the proximal colon, worms must be seen on the rectal 
mucosa to confirm the diagnosis of TDS,${ }^{8}$ and this defined a positive diagnosis for the study. A full course of the vermifuge mebendazole (100 $\mathrm{mg}$ twice daily for three days) was given. Stools were collected and sieved during and after chemotherapy. ${ }^{9}$ In addition to $T$ trichiura (maximum number recovered 3717), a minority of children passed Ascaris lumbricoides (maximum number 46); no child had hookworm (rare in young children in Jamaica today). ${ }^{10}$ A blood sample (5 ml in an EDTA prepared tube) was taken from each child before the colonoscopy and mebendazole treatment.

With the permission of the Ministries of Education and Health, and with the approval of the ethics committee of the Faculty of Medical Sciences, University of the West Indies, 20 normal control (NC) children (age range 4.3 to 11.3 years) were recruited from two schools in Kingston. Written consent was given by the parents of each child. To ensure that they did not have trichuriasis, a Kato smear ${ }^{11}$ was done on single stool samples, and children shedding any trichuris or other nematode eggs were excluded. Blood samples as for the cases were obtained from these 20 controls.

Sixteen further clinically referred children (age range 1.6 to 10.5 years) were designated as "disease controls" (DC). These children had no worms, but diarrhoea symptoms of at least one month's duration had provided the indication for an investigative colonoscopy; in no case did the history suggest a rapidly evolving clinical condition. Blood samples were obtained as for the TDS cases. The diagnosis in the DC group was ulcerative colitis (1), single juvenile colonic polyps (4), no specific diagnosis (11). With the exception of the ulcerative colitis, and excluding the examination of the four excised polyps, the routine histology of the mucosa showed mild inflammatory changes confined to the lamina propria and indistinguishable from the appearance in TDS except for the absence of worms. ${ }^{4}$ The case of ulcerative colitis produced no outlying values and during the data analysis its exclusion failed to affect any result materially. This case has therefore been included in the data below.

Standard blood counts were performed on admission for TDS and DC children, and haemoglobin estimation for NC children.

Plasma was obtained by centrifugation at $3000 \mathrm{rpm}$ for 10 minutes at $4^{\circ} \mathrm{C}$ and stored at $-20^{\circ} \mathrm{C}$ following the addition of aprotinin (final concentration about $100 \mathrm{U} / \mathrm{l})$. Three plasma proteins were assayed as representative respectively of rapid, intermediate, and late acute phase response: $C$ reactive protein, $\alpha_{1}$ antitrypsin, and caeruloplasmin. Albumin, total globulin, and fibrinogen were measured because they are often altered in chronic disease. Ferritin and transferrin were assayed as part of the assessment of iron status. Fibronectin was assayed for comparison with the state of primary malnutrition (studied at the TMRU), but this protein is also known to be altered in other acute disease states. ${ }^{12}{ }^{13}$ The concentrations of $C$ reactive protein, $\alpha_{1}$ antitrypsin, caeruloplasmin, fibrinogen, and transferrin were determined using the radial immunodiffusion (RID) technique. The RID kits were purchased from The Binding Site, Birmingham, United Kingdom, except for the NORPartigen Transferrin kit from Behringwerke, Marburg, Germany. Ferritin was measured with an immunoradiometric assay kit (DPC, California, USA) and fibronectin with an immonoturbidometric kit from BoehringerMannheim (Germany). For each of these assays at least two external calibrators supplied by the manufacturers were included. Albumin and total protein were measured on an autoanalyser (Spectrum, Abbott Laboratories, USA). The concentration of total globulin was inferred by subtraction. A separate sample maintained at room temperature was used for the measurement of plasma viscosity at $25^{\circ} \mathrm{C}$ with a Coulter Harkness viscometer (Coulter Electronics Ltd, Luton, United Kingdom). Viscosity was the only measurement repeated serially and was done on admission and at the six week and six month follow up visits on those patients available (TDS only).

\section{DATA ANALYSIS}

Differences among the interval scaled variables for the TDS, DC, and NC groups were examined by analysis of variance (ANOVA) if there was $>95 \%$ confidence that the variances were homogeneous by Bartlett's test. Log transformation was used if it improved the fit of a variate to the normal distribution. When variances differed excessively despite log transformation, the Kruskal-Wallis non-parametric test was used. $\chi^{2}$ for linear trend was used to test the ordered increase in one categorical variable (abnormal C reactive protein). Multiple regression analysis was used to identify the predictors of plasma viscosity among all the plasma protein concentrations. The EpiInfo 6 and Systat v. 5.0 packages were used for computation.

\section{Results}

The age distributions and the haematology results of the children are shown in table 1: the mean age of the NC group was significantly greater than that of the other two groups. Fifty five per cent of the NC children were marginally anaemic ( $\mathrm{Hb} 100-110 \mathrm{~g} / \mathrm{l})$, but $90 \%$ of the TDS and $81 \%$ of the DC children were either severely or marginally anaemic $(\mathrm{Hb}<110 \mathrm{~g} / \mathrm{l})$. The $\mathrm{Hb}$ minima in each group were NC 102, TDS 37, and DC $58 \mathrm{~g} / \mathrm{l}$. In neither disease group was the mean white cell count (WBC) suggestive of a widespread acute inflammatory state. The highest individual WBC was $22 \times$ $10^{\circ}$ per litre (in a child with TDS). The proportion of polymorphonuclear neutrophils was unremarkable.

Those proteins grouped together because of their known associations with disease and inflammatory states, including the acute phase proteins, are compared in table 2 . Significant differences among the three diagnostic groups were shown for concentrations of $\mathrm{C}$ reactive protein (Kruskal-Wallis three sample, $\mathrm{p}<0.01$; Mann-Whitney U test between groups, TDS $v$ $\mathrm{NC}$ and DC $v \mathrm{NC}, \mathrm{p}<0.01$; TDS $v \mathrm{DC}, \mathrm{NS})$; 
Table 1 Age and standard blood count of children on admission, means (95\% confidence interval)

\begin{tabular}{llll}
\hline & $N C$ & $D C$ & $T D S$ \\
\hline Age (years) ${ }^{\star}$ & $7.4(5.9,8.3)$ & $4.4(2.5,5.3)$ & $4.7(3.3,5.5)$ \\
Hb $(\mathrm{g} / 1) \dagger$ & $110.1(105,115)$ & $98.9(79,119)$ & $81.5(73,90)$ \\
WBC $\left(\times 10^{9}\right.$ per litre $)$ & ND & $10.1(6.8,13.4)$ & $11.1(9.9,12.3)$ \\
$\%$ Polymorph & ND & $44.6(27,63)$ & $43.6(35,51)$ \\
\hline
\end{tabular}

${ }^{\star} \mathrm{NC} v \mathrm{TDS} / \mathrm{DC} \mathrm{p}<0.001$. + Values differ significantly $(\mathrm{p}<0.01) . \mathrm{NC}=$ normal control; $\mathrm{DC}=$ disease control; TDS=trichuris dysentery syndrome; $\mathrm{ND}=$ not done.

Table 2 Proteins known to be associated with acute or chronic disease. Means (95\% confidence intervals) except where shown otherwise

\begin{tabular}{|c|c|c|c|}
\hline & $N C$ & $D C$ & $T D S$ \\
\hline CRP mg/l, median* (range) & $4.0(2$ to 75$)$ & 8.5 (2 to 82$)$ & $10.2(5$ to 60$)$ \\
\hline CRP $\%$ positive $f(\geq 10.0 \mathrm{mg} / \mathrm{l})$ & 20 & 40 & 51 \\
\hline$\alpha_{1}$ antitrypsin $₫ g / 1$ & $1.90(1.65,2.15)$ & -1 & $2.31(2.13,2.49)$ \\
\hline Caeruloplasmin $\ddagger \mathrm{mg} / \mathrm{l}$ & $383.7(333,434)$ & $483.9(440,528)$ & $410.2(366,454)$ \\
\hline Albumin $\mathrm{g} / \mathrm{l}$ & $39.2(38.1,40.3)$ & $39.8(37.3,42.3)$ & $37.7(37.6,37.8)$ \\
\hline Globulin $\delta \mathrm{g} / \mathrm{l}$ & $28.9(28.4,29.4)$ & $31.0(28.2,33.8)$ & $35.0(34.0,36.0)$ \\
\hline Fibrinogen g/l & $4.8(4.0,5.6)$ & $5.4(4.8,6.0)$ & $5.1(4.7,5.5)$ \\
\hline Fibronectin $\$ \mathrm{mg} / \mathrm{l}$ & $308.3(263,353)$ & $333.4(286,381)$ & $530.2(483,577)$ \\
\hline
\end{tabular}

${ }^{\star}$ Distribution highly skewed. $\$ p<0.01 .+\chi^{2}$ for linear trend: $\mathrm{p}=0.02 ; \neq \mathrm{p}<0.05$. $\uparrow$ Insufficient numbe assayed. $\mathrm{NC}=$ normal control; $\mathrm{DC}=$ disease control; $\mathrm{TDS}=$ trichuris dysentery syndrome; $\mathrm{CRP}=\mathrm{C}$ reactive protein.

Table 3 Proteins associated with iron status. Geometric means (95\% confidence interval)

\begin{tabular}{llll}
\hline & $N C$ & $D C$ & $T D S$ \\
\hline Ferritin $₫ \mu \mathrm{g} / 1$ & $22.4(20.9,23.9)$ & $5.9(4.4,7.4)$ & $4.3(2.8,5.8)$ \\
Transferrin $\mathrm{g} / 1$ & $0.25(0.24,0.26)$ & $0.29(0.24,0.34)$ & $0.34(0.27,0.41)$ \\
\hline
\end{tabular}

\$p<0.01.

$\mathrm{NC}=$ normal control; $\mathrm{DC}=$ disease control; TDS=trichuris dysentery syndrome

$\alpha_{1}$ antitrypsin (ANOVA, two sample, TDS $v$ NC, $\mathrm{p}<0.01$ ); caeruloplasmin (Kruskal-Wallis, $\mathrm{p}<$ 0.01 ; Mann-Whitney, DC $v$ TDS, $\mathrm{p}<0.01$; TDS $v$ NC, NS); total globulin (ANOVA, $\mathrm{p}<$ 0.01 ; post-ANOVA contrasts, TDS $v$ DC, $\mathrm{p}<$ 0.05 ; DC $v$ NC, NS), and fibronectin (Kruskal-Wallis, $\mathrm{p}<0.001$; Mann-Whitney, TDS $v$ DC, $\mathrm{p}<0.001 ; \mathrm{DC} v \mathrm{NC}, \mathrm{NS})$. There was no significant difference among groups for fibrinogen. The albumin concentration was marginally lower in the TDS group than in the other two, but the ANOVA was not significant ( $p$ $=0.08)$.

The ferritin and transferrin data (table 3) were consistent with the haematology and sug-

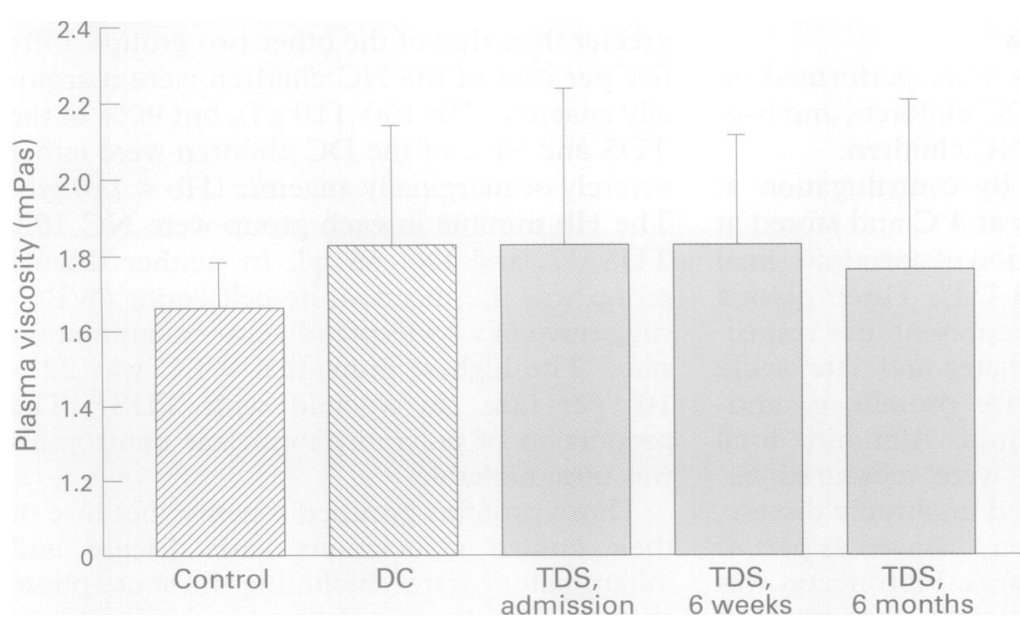

Figure 1 Plasma viscosity showing median (columns) and upper range (bars). Control = healthy children of phenotype $\mathrm{HbAA}$ from reference $14(n=15) ; D C=$ "disease control" ( $n=14$; not measured in two children); TDS = trichuris dysentery syndrome, on admission, six weeks after worm expulsion, and at six months follow up ( $n=27$; children only included if measurement repeated after both intervals). The fall is significant (see text). gested iron deficiency in both the TDS and DC groups.

Mean plasma viscosity on admission was raised but did not differ significantly between the TDS group (mean $1.91 \mathrm{mPa}, 95 \%$ confidence intervals $(\mathrm{CI}) 1.86,1.96)$ and the DC group (mean $1.84 \mathrm{mPa}, 95 \%$ CI 1.76, 1.92). Plasma viscosity was not measured in our NC children, but values for larger numbers of Jamaican children measured during the same period in the same laboratory have been published. ${ }^{14}$ The medians for the TDS and DC groups were relatively high when compared with the medians of children measured in this laboratory (regardless of sickle cell phenotype), but there is considerable overlap among the ranges, as shown in figure 1.

Six months after treatment for TDS the mean plasma viscosity $(1.81 \mathrm{mPa}, 95 \% \mathrm{CI}$ $1.74,1.86)$ remained raised; however, there was a significant fall when compared with the admission value (repeated measures ANOVA, $\mathrm{p}=$ 0.02 ; test for linearity, $\mathrm{p}=0.02$ ).

In the multiple regression analyses, plasma viscosity was the dependent variable while all plasma protein concentrations were offered as independent variables. Among the nine assayed, the only independent predictors were fibrinogen $(b=0.042, p<0.01)$ and total globulin $(b=0.012, p<0.001)$. These variables together explain $39 \%$ of the variance in plasma viscosity.

\section{Discussion}

Although TDS is an insidious and chronic, rather than acute, condition, our findings provided evidence of an acute phase response in progress in about half the patients at the arbitrary moment in the course of their disease when they were diagnosed and admitted for investigation. We based this on the $\mathrm{C}$ reactive protein results, for which an upper limit of normality of $10.0 \mathrm{mg} / \mathrm{l}$ has been accepted. ${ }^{7}{ }^{14}{ }^{15}$ However, four out of 20 control schoolchildren $(20 \%)$, whose current health had only been screened by stool microscopy and a short questionnaire to exclude parentally perceived gross disease, also had abnormal $\mathrm{C}$ reactive protein by this criterion. This high proportion may be spurious, representing only a stochastic consequence of the small denominator, as the median value for the NC group was clearly significantly less than for the disease groups (table 2).

Compared with the NC group the TDS patients also had a significantly raised mean $\alpha_{1}$ antitrypsin concentration. It has previously been stated that $\alpha_{1}$ antitrypsin is increased in response to nematode infection, ${ }^{16}$ and that it is a useful marker for bowel inflammation. Unfortunately, $\alpha_{1}$ antitrypsin measurements were unavailable for all but two of the DC children, so no comparison with this group is possible. The highest mean concentration of caeruloplasmin was in the DC group, with no significant mean rise in the TDS group, although the concentration among the TDS children was the most variable (ranging from 125.3 to $962.7 \mathrm{mg} / \mathrm{l})$. We conclude that there is evidence of a lack of any consistent caerulo- 
plasmin response to the type of colonic mucosal inflammation found in intense trichuriasis. Blom et $a l^{16}$ reported a statistically significant but small $(20 \%)$ decrease in mean caeruloplasmin concentration among Cambodian refugee children seven months after being freed of multiple infection by several species of intestinal nematode. These investigators ascribed the acute phase protein changes in their patients primarily to hookworm infection of the small intestine, and were unable to assess the contribution of trichuris and ascaris. The intestinal phase of hookworm infection has been noted elsewhere to induce an acute phase response, greater than the larval migration phase. $^{17}$

Ferritin is also an acute phase protein, ${ }^{18}$ but the TDS group, and to a lesser extent the DC group, were clearly severely iron deficient, as reflected by their haemoglobin levels. This was confirmed by serum iron measurements on the TDS and DC children (unpublished). Any tendency that may have existed for a rise in ferritin synthesis as a response to inflammation may have been overwhelmed by the depression in plasma concentration as a result of iron deficiency.

Our more striking and less expected finding was the clear demarcation in fibronectin level between the TDS and the other two groups. TDS is associated with both shortness of stature and underweight ${ }^{19}$ so fibronectin concentration, which is reduced in severe malnutrition, ${ }^{2021}$ might have been expected to be lower in TDS than in controls. In fact, our results show the reverse. Since there is recent evidence that TNF- $\alpha$ may be involved in the upregulation of the expression of fibronectin, ${ }^{22}$ it is possible that the increased plasma fibronectin concentration is a consequence of the increased plasma TNF- $\alpha$ in these patients. ${ }^{6}$ Further studies of fibronectin based on functional activity, for example collagen binding, in patients with intense trichuris or hookworm infection would be valuable; there is a possibility that the raised concentrations we report here represent an increase in epitopes available to the antibody used in the assay rather than a true increase in fibronectin concentration. This can occur as a result of proteolysis. ${ }^{23}$ This should not have occurred in vitro because of our use of aprotinin with stored samples, but might conceivably have occurred in vivo, as worms secrete proteolytic enzymes into the mucosa. ${ }^{24} 25$

There was an ordered increase in mean total plasma globulin from the NC through the DC to the TDS group. The total globulin will include globulins separately assayed such as $\alpha_{1}$ antitrypsin and fibrinogen as well as many others not assayed, and we have no information on the $\gamma$ globulin (antibody) component. Gilman et $a^{\beta}$ described reduced serum albumin in Malaysian children with intense trichuriasis, which they interpreted as a marker for malnutrition. We have shown a protein losing enteropathy in Jamaican children with TDS $^{3}$ using $\alpha_{1}$ antitrypsin clearance studies, and it is perhaps remarkable that the reduction in plasma albumin concentration in the Jamaican
TDS children was not greater. Possibly the explanation may lie in a difference in the diet available to Malaysian children in the 1970 s compared with Jamaican children around 1990.

Group differences in plasma protein profiles revealed by a cross sectional study such as this one could be due either to steady state differences in protein synthesis and secretion or to different mean phases of the systemic inflammatory response at the time of sampling. This issue could only be resolved by serial sampling of the TDS and DC children during the entire course of the evolution of their symptoms; however, their symptoms were well established and apparently constant at the time of investigation. Plasma viscosity, which has been used as a global marker of inflamma$\operatorname{tion}^{726}$ or disease activity, ${ }^{126}$ was widely variable in both the TDS and the DC children. A tendency to decline slowly following worm expulsion was seen. If a fall in plasma viscosity is an indication of an improvement in health, it was not on the scale of the resolution of anae$\mathrm{mia}^{27}$ or catch up in physical growth ${ }^{1827}$ in these children.

In summary, in this study we have shown some specific plasma protein characteristics of TDS and to some extent-through the use of "disease controls" as well as a "normal control" group-have been able to distinguish those associated with the specific nematode infection from those due to a locally prevalent mild chronic colitis. Although TDS is a nearly steady state condition, it is associated with an acute phase plasma protein response and this establishes that there is a systemic as well as a mucosal component of response to infection with Trichuris trichiura.

This study formed a joint component of studies on both trichuriasis and trace element nutrition funded by the Wellcome
Trust. We thank Dr Donald Simeon for reading the manuscript and providing statistical advice.

1 Cooper ES, Bundy DAP. Trichuris is not trivial. Parasitology Today 1988;4:301-6.

2 Ramsey FC. Trichuris dysentery syndrome. W Ind Med $\mathcal{f}$ 1962;11:235-9.

3 Cooper ES, Whyte-Alleng CAM, Finzi-Smith JS. MacDonald TT. Intestinal nematode infections in children: the patho-physiological price paid. Parasitology 1992:104 (suppl):S91-103.

4 MacDonald TT, Choy M-Y, Spencer J, Richman PI, Diss T, Hanchard B, et al. Histopathology and immunohistochemistry of the caecum in children with the Trichuris dysentery istry of the caecum in children with the

5 Cooper ES, Spencer J, Whyte-Alleng CAM, Cromwell O, Whitney P, Venugopal S, et al. Immediate hypersensitivity in the colon of children with chronic Trichuris trichiura dysentery. Lancet 1991;338:1104-7.

6 MacDonald TT, Spencer J, Murch SH, Choy M-Y, Venugopal S, Bundy DAP, et al. Mucosal macrophages and cytokine production in the colon of children with Trichuris trichiura dysentery. Trans $R$ Soc Trop Med Hyg 1994;88: 265-8.

7 Thompson D, Milford-Ward A, Whicher JT. The value of acute phase protein measurements in clinical practice. Ann Clin Biochem 1992;29:123-31.

8 Gilman RH, Chong YH, Davis C, Greenberg B, Virik HK, Dixon HB. The adverse consequences of heavy Trichuris Dixon HB. The adverse consequences of heavy Trich
infection. Trans $R$ Soc Trop Med Hyg 1983;77:432-8.

9 Bundy DAP, Thompson DE, Cooper ES, Blanchard J. Rate of expulsion of Trichuris trichiura with multiple and single dose regimens of albendazole. Trans $R$ Soc Trop Med Hyg 1985;79:641-4.

10 Speed JC, Culpepper V, Thompson DE, Henson R, Wint B, Bundy DAP. A community-based study of gastrointestinal helminth and protozoan infection in Western Jamaica. $W$ Ind Med F 1987;36:73-9. 
11 Martin LK, Beaver PC. Evaluation of Kato thick smear technique for quantitative diagnosis of helminth infections. Am ₹ Trop Med Hyg 1968;17:381-91.

12 Labrousse F, Dequirot A, Sos P, Le Quang NT. Plasma fibronectin depletion after cardiac surgery in children with or without cardiopulmonary bypass. $\mathcal{F}$ Clin Chem Clin Biochem 1986;24:441-4.

13 Torre D, Giola M, Zeroli C, Martegani R, Bonetta G, Ferrario $\mathrm{G}$. Circulating fibronectin and fibronectin receptor in children with pertussis. $\mathcal{F}$ Clin Pathol 1994;47:793-5.

14 Singhal A, Doherty JF, Raynes JG, McAdam KPWJ, Thomas PW, Serjeant BE, et al. Is there an acute-phase Thomas PW, Serjeant BE, et al. Is there an acute-phase response in

15 Gillespie SH, Dow C, Raynes JG, Behrens RH, Chiodini PL, McAdam KPWJ. Measurement of acute phase proteins for assessing severity of Plasmodium falciparum malaria. $\mathcal{F}$ Clin Pathol 1991;44:228-31.

16 Blom M, Prag J B, Norredam K. Alpha-1 acid glycoprotein, alpha- 1 antitrypsin and caeruloplasmin in human intestinal helminthiasis. Am f Trop Med Hyg 1979;28:76-83.

17 Stadnyk AW, Gauldie J. The acute phase protein response during parasitic infection. In: Ash C, Gallagher RB, eds. Immunoparasitology today. Cambridge: Elsevier Trends, 19mmunoparasitology today. Cambridge: Elsevier Trends,

18 Worwood $M$. 1979;10:171-204

19 Coop; syndrome. Trans $R$ Soc Trop Med Hyg 1995;89:653.
20 Chadwick SJD, Sim AJW, Dudley HAF. Changes in plasma fibronectin during acute nutritional deprivation in healthy human subjects. Br $\mathcal{F}$ Nutr 1986;55:7-12.

21 Yoder MC, Anderson DC, Gopalakrishna GS, Douglas SD, Polin RA. Comparison of serum fibronectin, prealbumin and albumin concentrations during nutritional rehabilitaand albumin concentrations during nutritional rehabilitation in protein-calorie malnourished infants. F Pediatr Gas-

22 Coito AJ, Binder J, Brown LF, de Sousa M, Van de Water L, Kupiec-Weglinski JW. Anti-TNF-alpha treatment downregulates the expression of fibronectin and decreases cellular infiltration of cardiac allografts in rats. $\mathcal{F}$ Immunol 1995 154:2949-58.

23 Kottgan E, Hoeft S, Muller C, Hell B. Functional analysis of plasma fibronectin with special consideration of binding interferences. $\mathcal{F}$ Clin Chem Clin Biochem 1986;24:541-9.

24 Lillywhite JE, Cooper ES, Needham CS, Venugopal S, Bundy DAP, Bianco AE. Identification and characterisation of excreted/secreted products of Trichuris trichiura. Parasite Immunol 1995;17:47-54.

25 Hotez P. Human hookworm infection. In: Farthing MJG, Keusch GT, Wakelin D, eds. Enteric infections. 2. Intestinal helminths. London, Chapman and Hall, 1995:129.

26 Hewlett SE, Haynes J, Shepstone L, Kirwan JR. Rheumatoid arthritis patients cannot accurately report signs of inflammatory activity. Br f Rheumatol 1995;34:547-53.

27 Callender JEM, Grantham-McGregor SM, Walker SP, Cooper ES. Treatment effects in Trichuris dysentery syndrome. Acta Paediatr 1994;83:1182-7. 